\title{
A Novel Integration of PCM with Wind-Catcher Skin Material in Order to Increase Heat Transfer Rate
}

\author{
Leila Seidabadi, Hossein Ghadamian* and Mohammad Aminy
}

Department of Energy, Material \& Energy Research Center, Tehran, Iran

\begin{abstract}
In this research, a comprehensive simulation study including 3-D Dynamic time-dependent has been performed for Phase Change Materials (PCMs) applicant as a thermal storage integrated with the wind-catcher-wall in order to reduce the temperature difference (As a sustainable cooling method) in the MATLAB open-source-code software. By means of 3-D Dynamic time-dependent, as a final finding, the temperature drop (Cooling purpose) was obtained 25 degrees at about 7 working hours. Passive cooling can be considered as a viable and attractive strategy for the sustainable concept, opposed to mitigation of energy consumption and Green House Gas (GHG) simultaneously. One of the traditional-old-age famous passive cooling systems that are still being applied nowadays is wind-catcher as an energy system. The wind catcher sustain natural ventilation and cooling in buildings through wind-driven airflow as well as temperature difference. Windcatchers can save the electrical energy used to provide thermal comfort during the hot climate in summer case of the year, especially during the peak hours contributed to energy carriers' consumptions. In this study, by proposing a new design of the windcatchers, attempts have been made to improve the energy efficiency of passive cooling methods. Besides, the application of new efficient methods for the purpose of thermal energy storage (PCM) as a sub-system is a chosen method to increase energy efficiency. By applying energy storage systems in addition to increase system energy performance and reliability, the target of reducing energy consumption is achieved.
\end{abstract}

(C) 2019. CBIORE-IJRED. All rights reserved Keywords: Passive Cooling, Temperature Drop, Analytic Mathematical Model, 3-D Dynamic Time-Dependent.

Article History: Received May 18 th 2018; Received in revised form October $5^{\text {th }}$ 2018; Accepted January $5^{\text {th }}$ 2019; Available online

How to Cite This Article: Seidabadi, L., Ghadamian, H, and Aminy, M. (2019) A Novel Integration of PCM with Wind-Catcher Skin Material in Order to Increase Heat Transfer Rate. Int. Journal of Renewable Energy Development, 8(1), 1-6.

https://doi.org/10.14710/ijred.8.1.1-6

\section{Introduction}

Energy conservation and sustainable development requirements in the building will make new concern in passive systems (Ghadamian et al. 2012). Passive cooling can be considered as a viable and attractive strategy for the sustainable concept, opposed to mitigation of energy consumption and Green House Gas (GHG) simultaneously. Natural ventilation, also called for passive cooling subsidiaries, uses natural outside air momentum energy and pressure differences to both passively cool and ventilate a building. Passive cooling is a building design strategy, energy saving and environmentally friendly technology that control the heat gain by preventing heat entering the living space by external heat sources in order to improve the indoor thermal comfort with low or null energy consumption attitude (Samuel et al 2013). Passive cooling is important because it can provide and make a self-push on fresh air without any fans. For warm and hot climates, it would meet a building's cooling loads without the application of mechanical air conditioning systems. This can be a considerable fraction of a building's total energy use. Passive cooling achieves high levels of natural convection and heat dissipation by utilizing a heat sink to maximize the radiation and convection heat transfer modes. In architectural point of view, natural resources like wind or soil are used as heat sinks to absorb or dissipate heat. Environmental heat sinks includes: 1. Outdoor air (heat transfer mainly by convection through openings), 2 . Water (heat transfer by evaporation inside and/or outside the building envelope), 3. Sky (during the night) (heat transfer by long-wave radiation through the roof and/or another surface adjacent to a building and ground (heat transfer by conduction through the building envelope) (Kamal 2012).

One of the traditional famous passive cooling systems that are still being applied up to now days is wind-catcher as an energy system (Fig. 1 and Fig. 2). For centuries, Wind-catchers were used in the past and are presently used in some regions of the Middle East and Egypt where hot and dry climate exist long, for the purpose of maintaining cool air circulation and cooling inside the buildings as well. In fact, the main purpose of windcatcher is to create natural ventilation and cooling by exchanging air. Those are between the outside and the building inside at an appropriate time during the day by manipulating pressure differences and the buoyancy

\footnotetext{
* Corresponding author: h.ghadamian@merc.ac.ir
} 
effects (Bahadori et al. 2014 and Sun 2017). Wind Energy is not the first renewable energy to improve air quality and combat greenhouse effect. Also, uses energy from natural sources and therefore helps to ensure energy independence (Naciri et al. 2017). Bahadori et al. (2002) used wetted columns and wetted surfaces in windcatchers. They showed that the air flow rate is higher on wetted surfaces than wetted columns when there is no wind blowing. The flow rate increases with an increase in the height of the tower (as a draft tube) in both cases. Wind-catchers with wetted surfaces perform best in areas with winds with very low speeds, whereas the towers with wetted columns perform best when there are winds with high velocities. Generally, the performance of these windcatchers can be improved appreciably by incorporating evaporative cooling inside of them. Dehghani-sanij et al. (2015) have been endeavored to improve the performance of wind-catchers and save energy by offering a new design. In their design, a flexible wind-catcher can rotate and set itself in the direction of the maximum wind speed. They have also proposed in areas where wind speed is low, to improve the efficiency of the system a solar chimney or a one-sided wind tower can be installed in another part of the building in the opposite direction. They suggested by using transparent materials could permit entering natural light into the building.

Interest in the use of phase change materials for cooling applications in recent decades due to the benefits of saving energy in the building sector has increased significantly (Waqas et al. 2018). Utilizing new materials that are capable of changing in different climatic conditions can be a good solution to save energy as a storage system and keep in accordance with environmental aspects that would be integrated with wind-catchers. To use these mentioned modern materials is one of the ways to increase system energy productivity. Including these materials are phase-change materials (PCMs) that have special and functional potential in the field of architecture and construction that can adapt to the environment and best respond to the environmental conditions.

In general, PCMs refer to materials that absorb and release thermal energy during the phase change process including melting and freezing. In the melting mode, these substances absorb a large amount of latent heat by a relatively constant temperature process. Inversely, when the freezing process happens, the stored heat in PCMs releases to the environment.

In order to this continuous charging capability, $\mathrm{PCM}$ can be considered as an ideal choice for conditions that have a temperature fluctuation and the temperature control is mandatory such as daily applications. In this regard, the usage of organic PCMs, paraffin for example, in low-to-medium temperature thermal energy storage can be referred to a suitable candidate (fang et al. 2014 and Jeong 2014).

Many reviews have been done to investigate energy storage technologies from a different point of view in latest three decades. However, in the last ten years, most researchers have focused on PCMs materials applications (Agyenim et al. 2010, Cabeza et al. 2011, Jamekhorshid et al. 2014, Marrigiannak et al. 2016 and Eslamnezhad et al. 2016). Chang et al. (2016), by presenting the macro packaging method, examined the PCM content of them and their phase transition temperature. The macropacked PCM was prepared using n-octadecane, neicosane, and n-docosane. By applying this method, the thermal conductivity obtained was higher than pure PCM thermal conductivity. As a result, due to the better thermal performance of n-octadecane, it was suggested that this material is used as a PCM in buildings.

Chernousov et al. (2016), by examining the challenge of the high-energy requirement to cool the offices on the hot summer days, has proposed using PCM in building envelope. By replacing the PCM in different parts of the building, they concluded that the PCM should be located in the inner envelope of the building and close to the interior. Therefore, their results illustrated that for an office building, a combined window and building envelope with PCM could be a great alternative to fully glazed curtain walls.

As the discussion of wind-catchers is not a new concern, the integration of PCMs with wind-catchers skin materials can be a novel point of view to be notified in this research. In this research, by integrated application of wind-catchers and PCMs, make effort to increase heat transfer rate, improve energy performance and the environmentally friendly attitude to partly-prevent electricity energy consumption for cooling purposes.

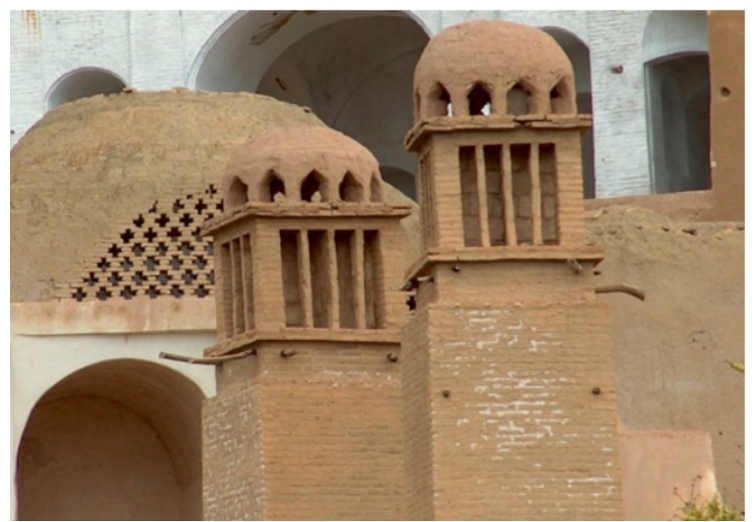

Fig. 1 Two four-sided wind-catcher enjoying cupolas (Pir-eNaraki) in Mehriz, Iran (Bahadori et al. 2014).

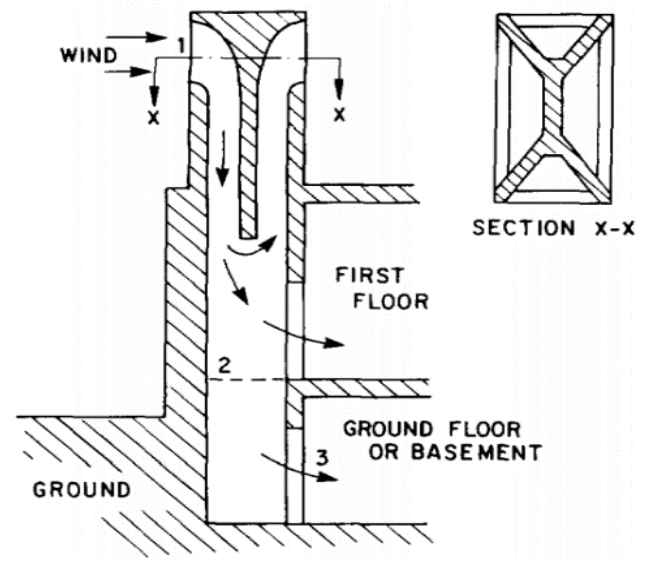

Fig. 2 Airflow pattern in a conventional Wind-Catcher (Bahadori 1985).

\section{System description}

A schematic demonstration of the system is shown in Figure 3. In this system, the passive cooling is performed by utilizing the two main integrated and contributed elements including wind-catcher and PCM. In addition to passive cooling and zero energy use in the wind-catchers, there is no positive pressure inside the building due to 
equal the air inlet and outlet, unlike the air conditioners especially the air coolers. Although, the air temperature leaving the wind-catcher in the building is almost equal to the ambient temperature in the shade. By these means, this air temperature and not enough momentum cannot meet the thermal comfort standards contributed to inhabitants of the building. As a need to achieve the level of standard to supply the ventilated air the wind-catchers should be assisted with other complementary systems. There are various ways to lower the ambient air temperature in the wind-catchers. One of the most widely used methods is the use of wetted surfaces and evaporative cooling. But unfortunately, the water scarcity issue is a major crisis in hot and dry areas, as opposed to this system so this method has been ignored and attempts to reduce the ambient temperature by using other approaches is proposed.

In this research, the thermal mass and thermal storage have been increased by raising the thickness of the wind-catcher walls, those are integrated with PCM applications, can be followed in Fig. 3. Considering the thickness, the walls act as a capacitor source of thermal storage and help control temperature throughout the day and achieve to lower leaving temperature to compare to the not integrated system. By insulating the outside of the walls, the amount of absorbed energy and daily heat exchanges are reduced. Therefore, helps the ambient air create the comfort during the day. As shown in Figure. 3, the wall is designed with a thickness of $35 \mathrm{~cm}$. In order to increase the thermal mass, the wall consists of two rows of bricks. Styrofoam is used as thermal insulation and preventing heat penetration into the wind-catcher. The walls at night exchange their stored heat energy with the environment, absorbing the thermal energy present throughout the day and keeping the ambient temperature at moderate and low levels. This will create enough comfort for the inhabitants of the building. During the night, considering the outer skin insolation at the walls, the wind-catcher heat energy would warm-up the inside air that acts like a chimney. That would assist to make an inductive momentum to move the air indoor of the building.

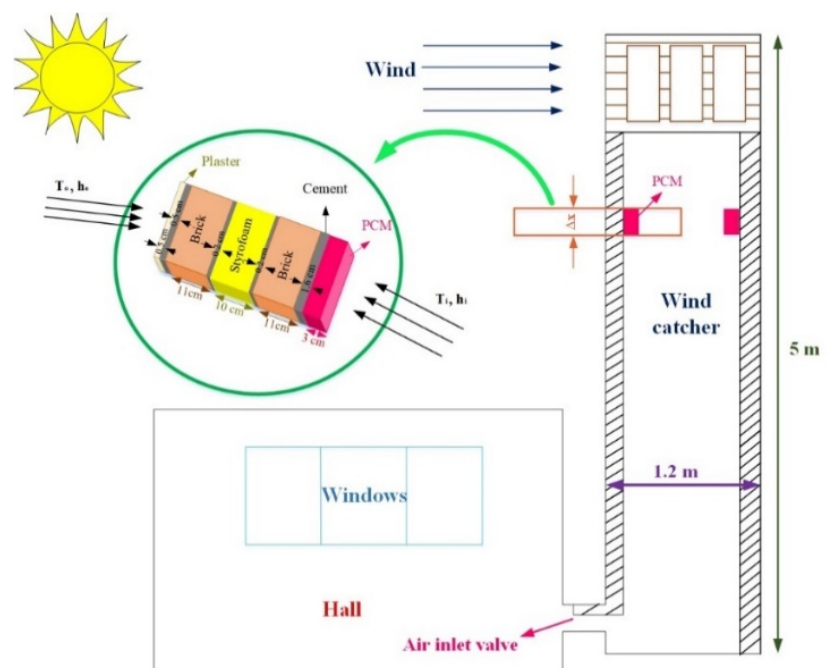

Fig. 3 Schematic of a Novel Integration of PCM with WindCatcher.

The wind-catcher is considered is common and currently used in hot and dry regions in Iran. Those are the four- side type with a square cross-section with dimension $1.2 \mathrm{x}$ $1.2 \mathrm{~m}^{2}$. The height of the wind-catcher is 5 meters (Fig. 1) (Bahadori et al. 2014). Meanwhile, PCM has storage properties much higher than walls. In this research, replacing PCMs in boxes in the around the inner wall that absorbs the heat of the inlet air to the wind-catcher. Hence, by the phase changing, reduces this temperature and then the cool air enters the building. The material used as a PCM is polyethylene glycol-1000, with a range of melting temperatures of $35-40^{\circ} \mathrm{C}$.

Each 24-hour cycle, the system absorbs energy through the wall and PCM during the day. At night, when the ambient air temperature drops sharply, storages (the wall and the PCM) are delivered the energy absorbed per day to the environment and is discharged. Therefore, the heat recovery is carried out again to operate to another cycle.

\section{System analytical modeling \& code development}

As an issue, applying 3-D dynamic simulation would assist to analyze phenomena further without spending more time and expense. In this research, by using the 3-D dynamic time-dependent method, it has been attempted to simulate the operation behavior of the PCM within a wind-catcher. The simulation approach can be separated into the following steps including 1 . The system geometry studies, 2. Reduce the temperature of inlet air, and 3. The variations regarding the system operation time intervals including PCM behavior. In this system, the key parameter is the temperature, which should be reduced to the proper value.

The model was developed in "MATLAB "open source software by PDSIMUL time-dependent function. The main challenge is the simulation of PCM since requiring differential calculations of the mass and heat transfer phenomenon when the substance changes its phase. To obtain more accurate results, the balance energy differential equations (Eq. 1) (Belhamadia et al. 2012). It is emphasized that have been solved analytically in the PCM contributed to the calculations of this research. Moreover, the codes are developed in the MATLAB software. Eq. 2 illustrates the temperature profiles of the polyethylene glycol-1000.

$$
\begin{aligned}
& \alpha(\varphi) \frac{\partial T}{\partial t}+\alpha(\varphi)(u \cdot \nabla T)+\rho_{l} L(u \cdot \nabla \varphi)+\rho_{l} L \frac{\partial \varphi}{\partial t}=\nabla \cdot(k(\varphi) \nabla T) \\
& T=\left[\sum_{k=1}^{k=\infty}\left(a_{k} \cosh \frac{k \pi y}{a}+b_{k} \sinh \frac{k \pi y}{a}\right) \sin \frac{k \pi x}{a}\right]+ \\
& {\left[\sum_{k=1}^{k=\infty}\left(d_{k} \cosh \frac{k \pi x}{b}+e_{k} \sinh \frac{k \pi x}{b}\right) \sin \frac{k \pi y}{b}\right]+} \\
& +\left[\sum_{k=1}^{k=\infty} \sum_{m=1}^{m=\infty} b_{m k} \sin \frac{k \pi x}{a} \sin \frac{m \pi x}{b} \cdot \exp \left(-S t \cdot\left(\frac{k^{2} \pi^{2}}{a^{2}}+\frac{m^{2} \pi^{2}}{b^{2}}\right)\right]\right.
\end{aligned}
$$

where:

- $\quad \alpha$ is Automatically regularized

- $\varphi$ is Phase change variable

- $\quad \mathrm{T}$ is Temperature $\left({ }^{\circ} \mathrm{C}\right)$

- $\mathrm{t}$ is Time (s)

- $u$ is Velocity $(\mathrm{m} / \mathrm{s})$

- $\quad$ l is Density of liquid $\left(\mathrm{kg} / \mathrm{m}^{3}\right)$

- $\mathrm{k}$ is Conductivity tensor $(\mathrm{S} / \mathrm{m})$ 
Finite Element Method (FEM) has developed the system simulation. Based on dynamic flow changes inside windcatcher and its walls, the numerical technique was initially developed in two dimensions ( $\mathrm{x}, \mathrm{y})$ and then extended in another dimension (z). Gridding makes discreet sections with a certain number of nodes $\left(m^{*} n\right)$ whereas Fig. 4 has illustrated in three dimensions by applying FEM.

The boundary conditions should be identified in the bottom and upper side those are predestined ambient condition at the height of 5 meters above the ground. As an innovative simplification, the right and left side boundary conditions were considered as symmetric. Therefore, the cross-section was intended for half of the wind-catcher from the right side of Fig. 4.

Furthermore, the temperature on the first section is equal to inlet air temperature of the wind-catcher. By using FEM, the initial nodes within the first section was converged to the answers. The PCM was considered around the wall in the specific box, which is placed in one meter of height as decussate. The PCM has not operated on the first section (Eq. 5-a). The nodes within the second section grid was solved by complex Eqs. 3, 4 and 5-b, where the sections are placed at a distance of 0.2 meter a height. This is repeated continually for the sections with PCM, as the Eqs. 3, 4 and 5-c were shown the sections without PCM. As an important issue, The PCM will be activated when the inlet air temperature to wind-catcher is more than the phase change temperature of the PCM. It should be noted, the equations have solved integrated and continually hence the PCM released energy during the time and geometry changes in each element.

$$
\begin{aligned}
& T_{4}(t, k)=\frac{[(2 * T(i, j-1)+T(i+1, j)+T(i-1, j))]}{4} \\
& m=43, n=22 \quad(i=15 \sim 29 \& j=22) \\
& T_{4}(t, k+1)=\varphi \cdot\left(T_{4}(t, k)-\frac{Q(t, k)}{U_{i} \cdot d x \cdot d z}\right)
\end{aligned}
$$

$$
Q(t, k)=\varphi \cdot\left(U \cdot A \cdot\left(T_{4}(t, k)-T_{5}(t, k)\right)\right)
$$

$T_{s}(t, k)=\frac{K_{p e n}(T(i+1, j)+T(i-1, j)+T(i, j-1))+U T(i, j+1)}{3 K_{p e m}+U_{i}}$

$m=43, n=22(i=15 \sim 29, j=14, k=1)$

$T_{5}(t, k)=\frac{\left[\frac{\rho_{3} \cdot A \cdot C \cdot T_{s}(t-1, k)}{d t}\right]+\lambda+\left[U_{i} T_{4}(t, k)\right]-\frac{E_{g}}{d z}+\mu}{\left(\frac{\rho_{3} \cdot A \cdot C}{d t}\right)+\left(3 \cdot K_{\text {pom }}\right)+\left(U_{i}\right)+\left(\frac{0.02 \dot{m}_{a} \cdot C}{d z^{2}}\right)}$

$m=43, n=22 \quad(i=15 \sim 29 \& j=14 \& k \neq 1)$

Where:

$$
\begin{aligned}
& \lambda=\left[K_{p c m} \cdot(T(i+1, j)+T(i-1, j)+T(i, j-1))\right] \\
& \mu=\left[\frac{0.02 \dot{m}_{a} \cdot C T_{5}(t, k-1)}{d z^{2}}\right] \\
& T_{5}(t, k)=\frac{K_{\text {wall }}(T(i+1, j)+T(i-1, j)+T(i, j-1))+U_{i} T(i, j+1)}{3 K_{p c m}+U_{i}} \\
& m=43, n=22(i=14 \sim 30, j=13, k \neq 1)
\end{aligned}
$$

\section{Results and discussions}

According to meteorology data, the ambient air during the hottest summer day of 2016 where is located at $\left(35^{\circ} 74^{\prime} 85^{\prime \prime} \mathrm{N}, 50^{\circ} 95^{\prime} 81^{\prime \prime} \mathrm{E}\right)$ coordinates, enter to windcatcher and its temperature profile is presented within Fig. 5. Since ambient air enters to wind-catcher, it encounters two scenarios include: 1 . the absence of PCM, 2. exposure in the vicinity of the PCM.

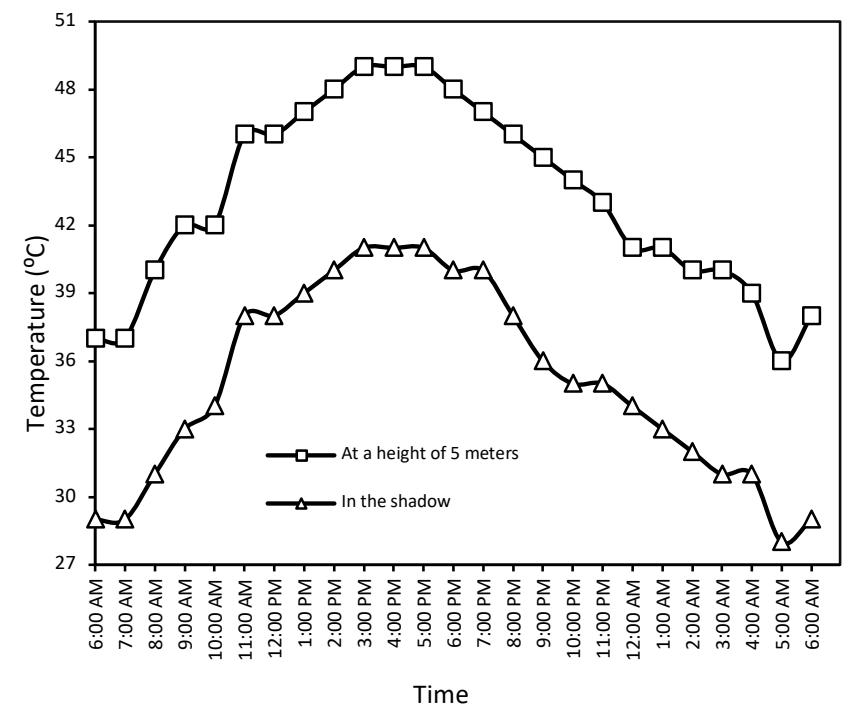

Fig. 5 Ambient air temperature. 
Fig. 6 and 7 are illustrated temperature profile in the absence of PCM and presence of it. As mentioned in previous part of the first section the PCM has not operated. Forasmuch as the amount of energy storage in the PCM is higher than the wall, therefore the amount of temperature drop in the sections with the presence of PCM is higher than the other sections, as well as the first section. Furthermore, PCM will not operate when the air temperature is less than phase change temperature of PCM. The times that the PCM operated, is shown in Fig. 7. Due to the closeness of the values, the temperature is shown in Fig. 7 for seven selected section (Fig. 4).

Fig. 8 is demonstrated internal wall temperature profile of wind-catcher. As shown in Fig. 8, the temperature variation in the wall is very small in different sections because the exterior wall is insulated, therefore, the temperature exchange by the outside to the inside will be very low.

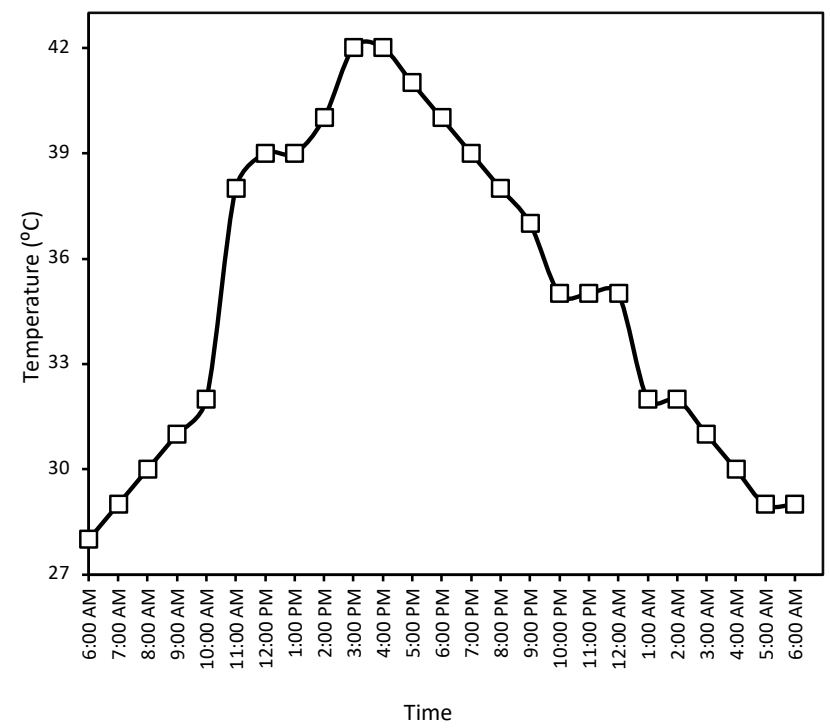

Fig. 6 Air temperature in the wind-catcher at the absence of PCM.

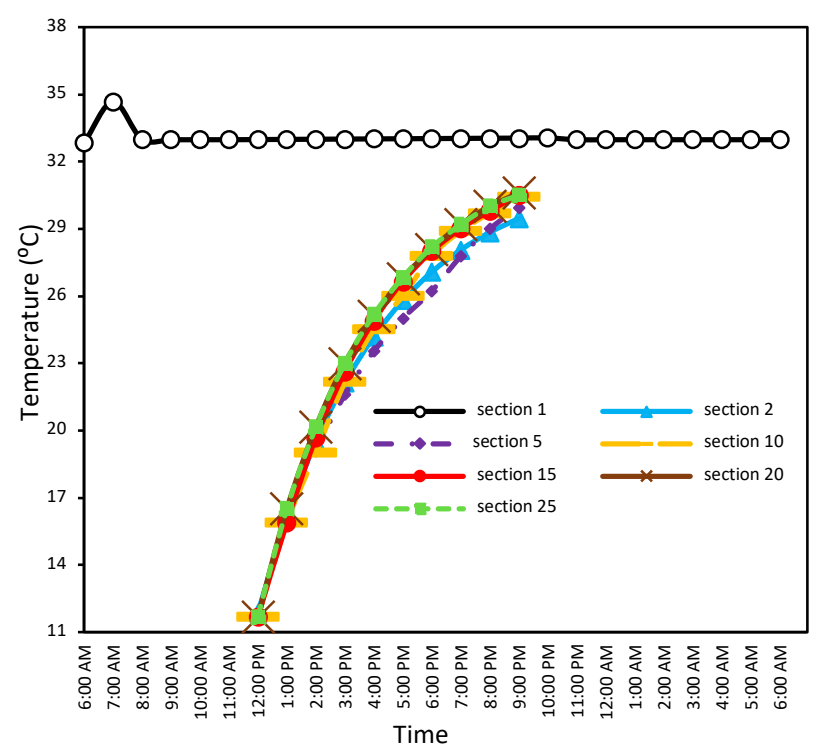

Fig. 7 Air temperature in the wind-catcher with the presence of PCM.

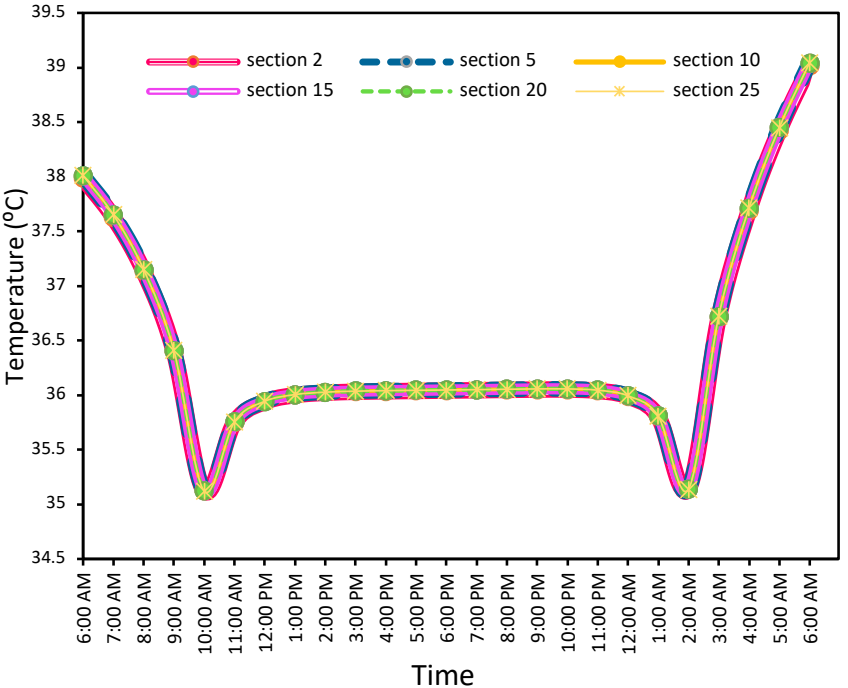

Fig. 8 Internal wall temperature of the wind-catcher.

\section{Conclusion}

In this research, a 3-D dynamic time-dependent model of a novel integration of PCM with wind-catcher skin materials is partly-analytically simulated and opensource code developed by MATLAB software. The research was done includes the analytical and numerical methods based on heat transfer phenomena. As a comparable conclusion in Fig. 5 and 6 air temperature reduction in wind-catcher without the presence of PCM, is not appropriate in comparison with ambient air temperature in the shadow, But it will be perfect with the presence of PCM application as illustrated in Fig. 7. As a final finding, the average of a temperature drop (Cooling purpose) was obtained 25 degrees at about 7 working hours (As shown in Fig. 7 12:00 P.M. 7:00 P.M.). Based on experiments, the system is able to reduce inlet air temperature without using any force convection utilizer as an energy consumer (Like fans \& etc.).

Therefore, by the application of this integrated proposed system within the hot and dry climates, a proper response to cooling air demand can be achieved.

\section{Acknowledgments}

The present study was supported by Materials and Energy Research Center (MERC) through grant No. 571395055 for the purpose of science development and acknowledge for the supports. This work is financially supported by Iranian Fuel Conservation Company (IFCO) for the purpose of science development and acknowledge for the supports.

\section{References}

Agyenim F., Hewitt N., Eames P. \& Smyth M. (2010) A review of materials, heat transfer and phase change problem formulation for latent heat thermal energy storage systems (LHTESS). Renewable and Sustainable Energy Reviews, 14, 615-628.

Bahadori M. (1985) An improved design of wind towers for natural ventilation and passive cooling. Solar Energy Journal, 35, 119-129.

Bahadori M. \& Pakzad A. (2002) Performance evaluation of new designs of wind towers. ASME Fluids Engineering Division Summer Meeting; Proceedings of ASME FEDSMi02. 
Bahadori M. \& Dehghani-sanij A. (2014) Wind Towers: Architecture, Climate and Sustainability, 1st Edn. Springer, London, England.

Belhamadia Y., Kane A. \& Fortin A. (2012) An enhanced mathematical model for phase change problems with natural convection. International Journal of Numerical Analysis and Modeling, 3, 192-206.

Cabeza L., Castell A., Barreneche C., de Gracia A. \& Fernández A. (2011) Materials used as PCM in thermal energy storage in buildings: A review. Renewable and Sustainable Energy Reviews, 15, 1675-1695.

Chang S., Wi S., Jeong S. \& Kim S. (2016) Thermal performance evaluation of macro-packed phase change materials (PCMs) using heat transfer analysis device. Energy and building Journal, 117, 120-127.

Chernousov A. \& Chan B. (2016) Numerical simulation of thermal mass enhanced envelopes for office buildings in subtropical climate zones. Energy and building Journal, 118, 214-225.

Dehghani-sanij A., Soltani M. \& Raahemifar K. (2015) A new design of wind tower for passive ventilation in buildings to reduce energy consumption in windy regions. Renewable and Sustainable Energy Reviews, 42, 182-195.

Eslamnezhad H. \& Rahimi A. B. (2016) Enhance heat transfer for phase-change materials in triplex tube heat exchanger with selected arrangements of fins. Applied Thermal Energy, 113, 813-821.

Fang X., Fan L., Ding Q., Yao X., Wu Y. \& Hou J. (2014) Thermal energy storage performance of paraffin-based composite phase change materials filled with hexagonal boron nitride Nanosheets. Energy Conversion and Management, 80, 103109.

Ghadamian H., Ghadimi M., Shakouri M., Moghadasi M. \& Moghadasi M (2012) Analytical solution for energy modeling of double skin facades building, Energy and Buildings, 50, 158-165.

Jamekhorshid A., Sadrameli S. \& Farid M. (2014) A review of microencapsulation methods of phase change materials (PCMs) as a thermal energy storage (TES) medium. Renewable and Sustainable Energy Reviews, 31, 531-542.

Jeong S. G., Lee J.H, Seo J. \& Kim S. (2014) Thermal performance evaluation of Bio-based shape stabilized PCM with boron nitride for energy saving. Int. Journal of Heat and Mass Transfer, 71, 245-250.

Kamal M.A. (2012) An Overview of Passive Cooling Techniques in Buildings: Design Concepts and Architectural Interventions. Journal of Civil Engineering \& Architecture, 55, 84-97.

Mavrigiannaki A. \& Ampatzi E. (2016) Latent heat storage in building elements: A systematic review on properties and contextual performance factors. Renewable and Sustainable Energy Reviews, 60, 852-866.

Naciri M., Aggour M. \& Ahmed W. A. (2017) Wind energy storage by pumped hydro station. Journal of Energy Systems, 1(1), $32-42$.

Samuel L., Nagendra S. \& Maiya M. P. (2013) Passive alternatives to mechanical air conditioning of building: A review. Journal of Building and Environment, 66, 54-64.

Sun Y., Guan Z. \& Hooman K. (2017) A review on the performance evaluation of natural draft dry cooling towers and possible improvements via inlet air spray cooling. Renewable and Sustainable Energy Reviews, 79, 618-637.

Waqas A., Ji J., Ali M. \& Alvi J. Z. (2018) Effectiveness of the phase change material-based thermal energy storage integrated with the conventional cooling systems of the buildings - A review. Proceedings of the Institution of Mechanical Engineers, Part A: Journal of Power and Energy, First Published 24 Jan 2018. 